\title{
Prevalence and Risk Factors for Mortality among COVID-19 Patients Hospitalized in Karachi City Pakistan
}

\author{
Salman Imtiaz, Ashar Alam, Faiza Saeed, Beena Salman, Shoukat Memon, \\ Javeria Chughtai, Shahzad Ahmed, and Sobia Tariq
}

\section{ABSTRACT}

Background: Corona virus disease (Covid -19) is the most contagious form of the disease of present time. Therefore, the risk factors which proliferate the spread and hinders the better outcome should be identified. There is gross difference in the spread and outcome of covid 19 in different region of the world. There is need to identify these factors in different communities of the globe.

Material and method: This is a retrospective observational cohort study of Covid -19 patients admitted during the study period. Institutional and ethical review board permission was taken prior to the study. Univariate and multivariate binary logistic regression was run and odds ratio with $95 \%$ confidence intervals were obtained. $P$ value of $\leq 0.05$ was considered significant. Outcome variables were recovery and death.

Results: There were 840 patients admitted between the study duration, while $704(83.8 \%)$ were included in our study. There were $491(69.7 \%)$ males and $213(30.3 \%)$ females. The mean age of the population was $54.6 \pm 15.5$ years. All continuous variables were categorized according to binary outcome (recovered and death) of patients. In Logistic regression analysis we found that patients in age group of 51-65 years died 2.5 time more than patients of age $\leq \mathbf{5 0}$ years. Similarly, the patients within age group of $>65$ died 4.5 times higher than $\leq 50$ years of age $(p<0.001)$. Male patients died 1.5 times more than females. Among all comorbid conditions HTN had significant effect on death, they died 1.5 times more than normotensive patients. In multivariate logistic regression analysis, the age groups had same significant effect on death when adjusted with other parameters, while effect of gender vanished. Similarly, the effect of HTN was also abolished when other factors were included in analysis.

Conclusion: We concluded that there is an urgent need of reevaluation of the traditional risk factors associated with viral epidemic and understanding the changing paradigm of epidemiology emerging out from this epidemic in both developed and developing counties. There is need of more data from developing world to elucidate the risk factors.

Keywords: risk factors, COVID-19, developing countries, Pakistan, pandemic, outcome.
Published Online: June 25, 2021

ISSN: $2736-5476$

DOI: $10.24018 /$ ejclinicmed.2021.2.3.46

Salman Imtiaz

MBBS, MRCP, FRCP, FCPS (Neph),

Senior Consultant, Head of The

Nephrology Dept. Chairperson Indus Nephrology Network. The Indus

Hospital, Korangi Crossing Karachi, Sindh, Pakistan.

(e-mail: salman.imtiaz ${ }^{\circledR}$ tih.org.pk)

Ashar Alam

FCPS(Neph), Associate Professor, Nephrology Department, The Indus Hospital, Korangi Crossing Karachi, Sindh, Pakistan.

(e-mail: ashar.alam@tih.org.pk)

Faiza Saeed*

FCPS (Neph), Nephrology Department, The Indus Hospital, Korangi Crossing Karachi, Sindh, Pakistan.

(e-mail: faiza.saeed@ ${ }^{\circledR}$ tih.org.pk)

Beena Salman

Epidemiologist and Biostatician, The Kidney Centre, Karachi, Sindh, Pakistan.

(e-mail: binasalman75@hotmail.com)

Shoukat Memon

FCPS, Consultant Nephrology Department, The Indus Hospital, Korangi Crossing Karachi, Sindh, Pakistan.

(e-mail: shoukat.memon@ ${ }^{\text {tih.org.pk }}$ Javeria Chughtai

FCPS, Registrar Nephrology Department, The Indus Hospital, Korangi Crossing, Karachi, Sindh, Pakistan.

(e-mail: javeria.chughtai@ ${ }^{\circledR}$ th.org.pk Shahzad Ahmed

Resident Nephrology Department, The Indus Hospital, Korangi Crossing, Karachi, Sindh, Pakistan.

(e-mail: shahzad.ahmed03@tih.org.pk Sobia Tariq

Resident Nephrology Department, The Indus Hospital, Korangi Crossing, Karachi, Sindh, Pakistan.

(e-mail: sobia.tariq@tih.org.pk)

*Corresponding Author 


\section{INTRODUCTION}

Corona virus disease (COVID-19) is the most contagious form of the disease of present time. The first case was diagnosed in China on 8 December 2019 and within a span of three month was declared a global emergency by WHO [1]. COVID-19 tends to spread symptomatically as well as asymptomatically with approximately $10 \%$ of diagnosed cases progress to critical disease [2].

The risk factors were evaluated in different studies, for example in U.K Biobank, analysis of 428,225 patients evaluated for modifiable and non-modifiable risk factors. After multivariable adjustment, modifiable risk factors were found to be high body mass index, smoking, physical fitness, hypertension (HTN), while non-modifiable risk factors were recognized to be older age, male sex, black ethnicity, socioeconomical deprivation, long standing illness and high Cystatin C [3]. In the same way, in other part of Europe prevalence of risk factors calculated among elderly population. The risk factors like HTN, chronic lung disease, cardiovascular disease, cancer, diabetes (DM) and obesity were evaluated. A total of $75.3 \%$ of the study population had at least one risk factor for severe COVID-19, 45.9\% had at least two factors and $21.2 \%$ had at least three risk factors. The prevalence of underlying medical conditions ranged from $4.5 \%$ for cancer to $41.4 \%$ for HTN, and the region-specific prevalence of having at least three risk factors ranged from $18.9 \%$ in Northern Europe to 24.6\% in Eastern Europe [4]. In China the risk factors for COVID-19 were recognized to be older age, White cell count, glucose level, fever, and asthma along with female gender in some group of the patients [5]. Similar risk factors were recognized in neighboring countries like Bangladesh and India [6], [7].

Despite the presence of similar risk factors in other part of the world, there is a gross variation in the diagnosis of new cases and cumulative deaths in different region of the world. According to $\mathrm{WHO}$, for example, the cumulative death in Americas and Europe till December 2020 was 872486(47\%) and $588770(32 \%)$ respectively as compared to Eastern Mediterranean 1220061 (6\%) and African region 43592(2\%). Similarly, the diagnosis of the cumulative cases were 36 million and 26 million in America and Europe respectively as compared with Eastern Mediterranean 4.9 million and Africa 1.9 million [8]

There might be some other risk factors than the traditional risk factors which were evaluated in above mentioned studies. For instance, countries with high values of disability adjusted life years, lost to cardiovascular diseases, cancer and chronic respiratory disease had highest value of fatality rate. Fatality rate is also found to be positively associated the share of population over 70 years, GDP (Gross domestic product) per capita and level of democracy [9]. Pakistan was thought to be the vulnerable to COVID-19 associated morbidity and mortality due to poor health care system, behavior of population [10]. But all predictions were failed when Pakistan showed a drastic decline in the incidence and mortality due to COVID-19 [11]. There seems a "reverse epidemiology" of COVID risk factors and outcome in the two worlds i.e., developing and developed world. This study examined the risk factors and outcome of COVID-19 infection in a population of a developing country like Pakistan.

\section{MATERIAL AND METHOD}

This is a retrospective observational cohort study of COVID-19 patients admitted in COVID-19 unit of Indus Hospital Karachi from 1st of March 2020 to 30th of Sep 2020. We included patients of all ages and the diagnosis of COVID19 was made by RT-PCR, performed through nasopharyngeal extraction of viral specimen. Permission from the institutional ethical review committee was taken prior to conduction of study. History, clinical examination, laboratory investigations, and ultrasound imaging of the kidneys was acquired from the Health Management Information System (HMIS) record of the patients. Data was collected on a structured proforma which included variables like age, gender, comorbid conditions, clinical presentation, hemodynamic status, and lab parameters. Outcome variables were recovery, and death.

Statistical analysis: The data was entered and analyzed in IBM SPSS version 21. Cleaning and coding of data was done prior to analysis. Mean \pm Std were computed for continuous variables, while categorical parameters were expressed in frequencies with percentages. Cross tabulation was done to see the distribution of variables according to outcome of disease, then to see the observe amount of effect of parameters on outcome of COVID patients, univariate and multivariate binary logistic regression was run and odds ratio with $95 \%$ confidence intervals were obtained. $\mathrm{P}$ value of $\leq$ 0.05 was considered significant.

\section{RESUlts}

There were 840 patients admitted between March to 30 September 2020, while $704(83.8 \%)$ were included in our study. Male were 491(69.7\%), while 213(30.3\%) were female (Fig. 1).

The mean age of our patients was $54.6 \pm 15.5$ years with the minimum of 1 years and maximum of 95 years and males were predominant $491(69.7 \%)$. The most common symptom of COVID was shortness of breath 520(74\%) while the most prevalent sign was fever 211(30\%) (Table I).

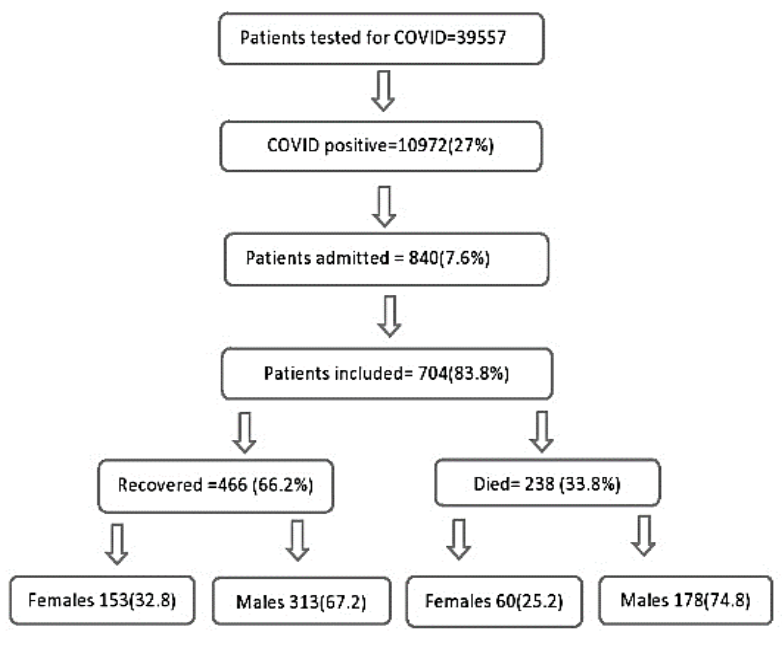

Fig. 1. Distribution of population. 
TABLE I: DEMOGRAPHIC AND CLINICAL PARAMETERS OF PATIENTS $=704$

\begin{tabular}{cc}
\hline Variables & Mean \pm std/n $(\%)$ \\
Age & $54.6 \pm 15.5$ \\
Male/Female & $491(69.7) / 213(30.3)$ \\
Pulse(beats/min) & $90 \pm 19.4$ \\
Systolic BP (mm of Hg) & $129.4 \pm 22.6$ \\
Diastolic BP (mm of Hg) & $75.2 \pm 14$ \\
RR (breaths/min) & $24.4 \pm 6.1$ \\
Fever & $211(30)$ \\
SOB & $520(74)$ \\
Cough & $307(45)$ \\
Oliguria & $136((19.3)$ \\
Confusion & $89(12.6)$ \\
Drowsiness & $84(11.9)$ \\
Edema & $67(9.5)$ \\
Vomiting & $56(8)$ \\
volume depletion & $38(5.4)$ \\
Anorexia & $34(4.8)$ \\
Nausea & $34(4.8)$ \\
Seizures & $6(0.9)$ \\
ACEI/ARB & $85(12.1)$ \\
Aspirin & $199(28.3)$ \\
Statins & $153(21.7)$ \\
\hline
\end{tabular}

BP Blood pressure, RR Respiratory rate, SOB Shortness of breath, ACEI Angiotensin converting enzyme inhibitor, ARB Angiotensin receptor blocker.

TABLE II: DistRIBUTION OF AGE, GENDER, COMORBID, COMPLICATIONS AND TREATMENT ACCORDING TO OUTCOME OF COVID-19 PATIENTS

\begin{tabular}{|c|c|c|c|c|}
\hline Variables & & $\begin{array}{c}\text { Recovered } \\
466(66.2 \%)\end{array}$ & $\begin{array}{c}\text { Died } \\
238(33.8 \%) \\
\end{array}$ & Total \\
\hline \multirow{3}{*}{ Age(years) } & $\leq 50$ & $200(42.9)$ & $47(19.7)$ & $247(35.1)$ \\
\hline & $51-65$ & $189(40.6)$ & $113(47.5)$ & $302(42.9)$ \\
\hline & $>65$ & $77(16.5)$ & $78(32.8)$ & $155(22)$ \\
\hline \multirow{2}{*}{ Gender } & Male & $313(67.2)$ & $178(74.8)$ & 491(69.7) \\
\hline & Female & $153(32.8)$ & $60(25.2)$ & $213(30.3)$ \\
\hline \multicolumn{5}{|c|}{ Comorbid } \\
\hline \multirow{2}{*}{ Diabetes mellitus } & Yes & $196(42.1)$ & $116(48.7)$ & $312(44.3)$ \\
\hline & No & $270(57.9)$ & $122(51.3)$ & $392(55.7)$ \\
\hline \multirow{2}{*}{ Hypertension } & Yes & $265(56.9)$ & $158(66.4)$ & $423(60.1)$ \\
\hline & No & $201(43.1)$ & $80(36.6)$ & 281(39.9) \\
\hline \multirow{3}{*}{$\begin{array}{l}\text { Ischemic heart } \\
\text { disease }\end{array}$} & Yes & $76(16.3)$ & $52(21.8)$ & $128(18.2)$ \\
\hline & No & $390(83.7)$ & $186(78.2)$ & $576(81.8)$ \\
\hline & \multicolumn{4}{|c|}{ Complications } \\
\hline \multirow{2}{*}{ Acute kidney injury } & Yes & $61(13.1)$ & $147(61.8)$ & $208(29.5)$ \\
\hline & No & $405(86.9)$ & $91(38.2)$ & $496(70.5)$ \\
\hline \multirow{2}{*}{$\begin{array}{l}\text { Acute coronary } \\
\text { syndrome }\end{array}$} & Yes & $13(2.8)$ & $15(6.3)$ & $28(4)$ \\
\hline & No & $453(97.2)$ & $223(93.7)$ & $676(96)$ \\
\hline \multirow{2}{*}{$\begin{array}{l}\text { Congestive cardiac } \\
\text { failure }\end{array}$} & Yes & $19(4.1)$ & $16(6.7)$ & $35(5)$ \\
\hline & No & $447(95.9)$ & $222(93.3)$ & $669(95)$ \\
\hline \multirow{2}{*}{$\begin{array}{c}\text { Peripheral vascular } \\
\text { disease }\end{array}$} & Yes & $7(1.5)$ & $7(2.9)$ & $14(2)$ \\
\hline & No & $459(98.5)$ & $231(97.1)$ & $690(98)$ \\
\hline \multirow{3}{*}{$\begin{array}{c}\text { Thromboembolic } \\
\text { event }\end{array}$} & Yes & $12(2.6)$ & $21(8.8)$ & $33(4.7)$ \\
\hline & No & $454(97.4)$ & $217(91.2)$ & $671(95.3)$ \\
\hline & & reatment & & \\
\hline \multirow{2}{*}{ Methylprednisolone } & Yes & $315(67.6)$ & $198(83.2)$ & $513(72.9)$ \\
\hline & No & $151(32.4)$ & $40(16.8)$ & $191(27.1)$ \\
\hline \multirow{2}{*}{ Remdesivir } & Yes & $67(14.4)$ & $63(26.5)$ & $130(18.5)$ \\
\hline & No & $399(85.6)$ & $175(73.5)$ & $574(81.5)$ \\
\hline \multirow{2}{*}{ Tocilizumab } & Yes & $61(13.1)$ & $79(33.2)$ & $140(19.9)$ \\
\hline & No & $405(86.9)$ & $159(66.8)$ & $564(80.1)$ \\
\hline \multirow{2}{*}{ Hydroxychloroquine } & Yes & $62(13.3)$ & $41(17.2)$ & $103(14.6)$ \\
\hline & No & $404(86.7)$ & 197(82.2) & $601(85.4)$ \\
\hline \multirow{2}{*}{ Vasopressin } & Yes & $16(3.4)$ & $184(76.5)$ & $198(28.1)$ \\
\hline & No & $450(96.6)$ & $56(23.5)$ & $506(71.9)$ \\
\hline \multirow{2}{*}{ Ventilatory support } & Yes & $15(3.2)$ & $170(71.4)$ & $185(26.3)$ \\
\hline & No & $451(96.8)$ & $68(28.6)$ & $519(73.7)$ \\
\hline \multirow{2}{*}{$\begin{array}{l}\text { Hemodialysis } \\
\text { support }\end{array}$} & Yes & $86(18.5)$ & $70(29.4)$ & $156(22.2)$ \\
\hline & No & $38(81.5)$ & $168(70.6)$ & $548(77.8)$ \\
\hline
\end{tabular}

For analysis purpose, we categorized all continuous variables and obtained their frequencies according to binary outcome (recovered and death) of patients, suffering from COVID-19. We observed that majority of patients belonged to age group of 51-65 years 302(42.9\%) and hence majority of patients who died were from the same age group $113(47.5 \%)$. Similarly male patients were more in number $491(69.7 \%)$ and they encountered death more than female patients $178(74.8 \%)$ vs $60(25.2 \%)$, respectively. The most common comorbid was HTN 423(60.1\%) in our patients and these patients were more prone to death than normotensive $66.4 \%$ vs $36.6 \%$. Acute kidney injury (AKI) was the most prevailing complication of COVID-19 in our cohort $208(29.5 \%)$ and these patients suffered death more as compared to patients without AKI and other complications 147(61.8). Patients were treated with different medications according to their clinical status and progression of disease. Methylprednisolone was given to 513(72.9\%) patients in which 315 recovered while 198 died. while remaining of the treatment like Remdesivir, Tocilizumab and Hydroxychloroquine were given to a smaller number of patients. Patients who developed severe or critical disease and required support in the form vasopressors, ventilator and hemodialysis succumbed to death more as compared to those who did not need these supports $184(76.5 \%), 170(71.4 \%)$ and $70(29.4 \%)$, respectively (Table II).

Our majority of patients who died had high TLC $182(76.5 \%)$ in contrast to those who had normal count $56(16.4 \%)$. Likewise, high number of patients had lymphopenia 594(85.4\%) and therefore more death was observed in those who had low lymphocyte count $221(37.2 \%)$ than those who had normal counts $17(7.1 \%)$. Similarly, low albumin was more prevalent in COVID patients 499(63.8\%), among patients who died, 199(83.6\%) were hypoalbuminic as compared to the patients with normal level 39(16.4\%). Low bicarbonate levels were also more frequently observed in this group of patients as $482(68.5 \%)$ and $184(77.3 \%)$ patients died in comparison with those who had high or normal bicarbonate levels (Table III). All laboratory parameters related to COVID-19 infection were raised in our patients and the patients who died of COVID had more raised levels of Lactate dehydrogenase (LDH), C-reactive protein (CRP), Ferritin and D-Dimer (Table III).

In Logistic regression analysis we found that patients in age group of 51-65 years died 2.5 time more than patients of age $\leq 50$ years. Similarly, the patients within age group of $>65$ died 4.5 times higher than $\leq 50$ years of age $(p<0.001)$. Male patients died 1.5 times more than females. Among all comorbid conditions HTN had significant effect on death, they died 1.5 times more than normotensive patients. Acute kidney injury was the most dreadful complication with COVID-19 infection, as the death was 10.7 times more in patients with AKI than with non-AKI $(\mathrm{P}<0.001)$. Similarly, patients who suffered with acute coronary syndrome (ACS) and thromboembolic event (TEE) died 2.3 and 3.7 times more, respectively. Patients with sepsis (TLC >11000) died 5.2 times more than the patients with normal leucocyte count $(\mathrm{p}<0.0001)$.In the same way, low level of platelets, lymphocytes and albumin had 2.9,3.2 and 4.4 times, respectively died more than the patients who had normal range of these labs $(p<0.001)$.Electrolytes disturbance also had an impact on mortality as we found that patients who had hypernatremia, hyperkalemia, hypobicarbonatemia (acidosis) and hyperbicarbonatemia (alkalosis) died 17.4,4.4,2.5 and 2 times more, respectively than those who had normal levels of 
these electrolytes $(\mathrm{p}<0.001)$. Patients with high levels of LDH, Ferritin, D-Dimer and Procalcitonin had 11.2, 3.6, 6.7 and 4.1 times more death, respectively $(\mathrm{p}<0.001)$. To adjust the independent effect of variables on outcome of COVID-19 we did multivariate logistic regression analysis and kept all these variables in final model and found that age groups had same significant effect on death when adjusted with other parameters, while effect of gender vanished. Similarly, the effect of HTN was also abolished when other factors were included in analysis.

\begin{tabular}{|c|c|c|c|c|}
\hline \multicolumn{2}{|c|}{ Laboratory variables } & $\begin{array}{c}\text { Recovered } \\
466(66.2 \%)\end{array}$ & $\begin{array}{c}\text { Died } \\
238(33.8 \%) \\
\end{array}$ & Total \\
\hline \multirow{2}{*}{ Hemoglobin $(\mathrm{gm} / \mathrm{dl})$} & $<12$ & $180(38.6)$ & $101(42.4)$ & $281(39.9)$ \\
\hline & $\geq 12$ & $286(61.4)$ & 137(57.6) & $423(60.1)$ \\
\hline \multirow{2}{*}{ Total leucocyte count } & $>11$ & $180(38.6)$ & $182(76.5)$ & $362(51.4)$ \\
\hline & $\leq 11$ & $28(61.4)$ & $56(16.4)$ & $342(48.6)$ \\
\hline \multirow{2}{*}{ Platelets } & $<150$ & $57(12.2)$ & $68(28.6)$ & $125(17.8)$ \\
\hline & $\geq 150$ & $409(87.9)$ & $170(71.4)$ & $579(82.2)$ \\
\hline \multirow{2}{*}{ Lymphocyte count } & $<20 \%$ & $373(80)$ & $221(37.2)$ & $594(84.4)$ \\
\hline & $\geq 20 \%$ & $93(20)$ & $17(7.1)$ & $111(15.6)$ \\
\hline \multirow{2}{*}{$\operatorname{Albumin}(\mathrm{gm} / \mathrm{dl})$} & $<3.5$ & $250(53.6)$ & $199(83.6)$ & $499(63.8)$ \\
\hline & $\geq 3.5$ & $216(46.4)$ & $39(16.4)$ & $255(36.2)$ \\
\hline \multirow{4}{*}{ Sodium (meq/L) } & Eunatremia & $330(70.8)$ & $131(55)$ & $461(65.5)$ \\
\hline & Hyponatremia & $126(27)$ & $38(16)$ & $164(23.3)$ \\
\hline & Hypernatremia & $10(2.1)$ & $69(29)$ & $79(11.2)$ \\
\hline & Normokalemia & $407(87.3)$ & $166(69.7)$ & $573(81.4)$ \\
\hline \multirow[t]{3}{*}{ Potassium (meq/L) } & Hyperkalemia & $36(7.7)$ & $64(26.9)$ & $100(14.2)$ \\
\hline & Hypokalemia & $23(4.9)$ & $8(3.4)$ & $31(4.4)$ \\
\hline & Normal & $115(24.7)$ & $28(11.8)$ & $143(20.3)$ \\
\hline \multirow[t]{3}{*}{ Bicarbonate (meq/L) } & Low & 298(63.9) & $184(77.3)$ & $482(68.5)$ \\
\hline & High & $53(11.4)$ & $26(10.9)$ & $79(11.2)$ \\
\hline & $<250$ & $51(10.9)$ & $5(2.1)$ & $56(8)$ \\
\hline \multirow[t]{2}{*}{ Lactate dehydrogenase $(\mathrm{u} / \mathrm{l})$} & $250-500$ & $259(55.6)$ & $62(26.1)$ & $321(45.6)$ \\
\hline & $>500$ & $156(33.5)$ & $171(71.8)$ & $327(46.4)$ \\
\hline \multirow{2}{*}{$\mathrm{C}$ reactive protein $(\mathrm{mg} / \mathrm{L})$} & $>10$ & 427(91.6) & $224(94.1)$ & $651(92.5)$ \\
\hline & $\leq 10$ & $39(8.4)$ & $14(5.9)$ & $53(7.5)$ \\
\hline \multirow{2}{*}{ Ferritin(ng/ml) } & $>250$ & $403(86.5)$ & $228(95.8)$ & $631(89.6)$ \\
\hline & $\leq 250$ & $63(13.5)$ & $10(4.2)$ & $73(10.4)$ \\
\hline \multirow{2}{*}{ D-Dimer } & $>0.4$ & $294(63.1)$ & $219(92)$ & $513(72.9)$ \\
\hline & $\leq 0.4$ & $172(36.9)$ & $19(8)$ & $191(27.1)$ \\
\hline \multirow{2}{*}{ Procalcitonin(ng/ml) } & $>0.49$ & 193(41.4) & 177(74.4) & $370(52.6)$ \\
\hline & $\leq 0.49$ & $273(58.6)$ & $61(25.6)$ & $334(47.4)$ \\
\hline
\end{tabular}

TABLE IV: AMOUNT OF EFFECT OF VARIABLES ON DEATH OF COVID PATIENTS

\begin{tabular}{|c|c|c|c|c|c|c|}
\hline \multirow[b]{2}{*}{ Variables } & \multicolumn{3}{|c|}{ Univariate analysis } & \multicolumn{3}{|c|}{ Multivariate analysis } \\
\hline & $\begin{array}{l}\text { Odds } \\
\text { ratio }\end{array}$ & 95\% CI Lower-Upper & $\mathrm{p}$ value & Odds ratio & 95\% CI Lower- Upper & $\mathrm{p}$ value \\
\hline Age 51-65 years & 2.5 & $1.7-3.8$ & $<0.001$ & 2 & $1.1-3.6$ & 0.024 \\
\hline Age $>65$ years & 4.3 & $2.8-6.7$ & $<0.001$ & 3.2 & $1.6-6.4$ & 0.001 \\
\hline Male & 1.5 & $1.01-2.1$ & 0.035 & 1.2 & $0.68-2.1$ & 0.54 \\
\hline Diabetes mellitus & 1.3 & $0.96-1.8$ & 0.092 & 0.9 & $0.55-1.5$ & 0.695 \\
\hline Hypertension & 1.5 & $0.08-2.1$ & 0.015 & 1.1 & $0.62-1.8$ & 0.845 \\
\hline Ischemic heart disease & 1.4 & $0.97-2.1$ & 0.072 & 0.84 & $0.44-1.6$ & 0.599 \\
\hline Acute kidney injury & 10.7 & $7.4-15.6$ & $<0.001$ & 4 & $2.4-6.8$ & $<0.001$ \\
\hline Acute coronary syndrome & 2.3 & $1.1-5$ & 0.028 & 3.9 & $1.3-11.7$ & 0.015 \\
\hline Congestive cardiac failure & 1.7 & $0.86-3.4$ & 0.13 & 0.48 & $0.17-1.3$ & 0.152 \\
\hline Peripheral vascular disease & 2 & $0.69-5.7$ & 0.204 & 0.5 & $0.11-2.4$ & 0.381 \\
\hline Thromboembolic event & 3.7 & $1.8-7.6$ & $<0.001$ & 2.7 & $0.85-8.6$ & 0.093 \\
\hline Hemoglobin $<12 \mathrm{mg} / \mathrm{dl}$ & 1.2 & $0.85-1.6$ & 0.329 & 0.76 & $0.45-1.3$ & 0.329 \\
\hline Total leucocyte count $>11 \mathrm{~g} / \mathrm{dl}$ & 5.2 & $3.6-7.4$ & $<0.001$ & 2.8 & $1.7-4.7$ & $<0.001$ \\
\hline Platelets $<150$ & 2.9 & $1.9-4.3$ & $<0.001$ & 1.8 & $0.97-3.5$ & 0.061 \\
\hline Lymphocyte count $<20 \%$ & 3.2 & $1.9-5.6$ & $<0.001$ & 2.1 & $0.88-4.9$ & 0.095 \\
\hline Albumin $<3.5 \mathrm{~g} / \mathrm{dl}$ & 4.4 & $3-6.5$ & $<0.001$ & 3.6 & $2.1-6.4$ & $<0.001$ \\
\hline Hyponatremia & 0.76 & $0.5-1.2$ & 0.195 & 0.32 & $0.17-0.59$ & $<0.001$ \\
\hline Hypernatremia & 17.4 & $8.7-34$ & $<0.001$ & 3.9 & $1.7-8.7$ & 0.001 \\
\hline Hypokalemia & 0.85 & $0.37-1.9$ & 0.705 & 1.8 & $0.58-5.3$ & 0.316 \\
\hline Hyperkalemia & 4.4 & $2.8-6.8$ & $<0.001$ & 2.2 & $1.1-4.3$ & 0.025 \\
\hline Hypobicarbonatemia & 2.5 & $1.6-3.9$ & $<0.001$ & 1.8 & $0.94-3.5$ & 0.075 \\
\hline Hyperbicarbonatemia & 2 & $1.1-3.8$ & 0.025 & 1.6 & $0.64-4.2$ & 0.304 \\
\hline Lactate dehydrogenase $250-500 \mathrm{U} / \mathrm{L}$ & 2.4 & $0.94-6.4$ & 0.068 & 2.9 & $0.86-9.9$ & 0.085 \\
\hline Lactate dehydrogenase $>500 \mathrm{U} / \mathrm{L}$ & 11.2 & $4.4-28.7$ & $<0.001$ & 7.7 & $2.3-26.3$ & 0.001 \\
\hline$C$ reactive Protein $>10$ & 1.5 & $078-2.75$ & 0.239 & 1 & $0.39-2.7$ & 0.97 \\
\hline Ferritin $>250$ & 3.6 & $1.8-7.1$ & $<0.001$ & 0.69 & $0.25-1.9$ & 0.47 \\
\hline D Dimer $>0.49$ & 6.7 & $4.1-11.2$ & $<0.001$ & 2.6 & $1.3-5.1$ & 0.006 \\
\hline Procalcitonin $>0.5$ & 4.1 & $2.9-5.8$ & $<0.001$ & 2.4 & $1.5-4$ & 0.001 \\
\hline
\end{tabular}


Among all complications AKI and ACS had remain significant effect in multivariate analysis to, although odds ratio of AKI decreased from 10.7 to 4.0. On the contrary, the odds ratio of ACS was increased up to 3.9 times. The odds ratio of high total leucocyte count (TLC) and low albumin also decreased in adjusted model but retained their significant effect on death. On the other hand, low platelets and lymphopenia lost their significant impact on outcome in multivariate analysis. Both hypernatremia and hyperkalemia had significant impact on death in multivariate model too, although their odds ratio were decreased. On the other hand, bicarbonate lost its effect on outcome of patients in adjusted analysis. Patients with high levels of LDH, D-Dimer and Procalcitonin maintained their significant impact on death in adjusted analysis, while effect of Ferritin was eliminated when adjusted with other factors (Table IV.)

\section{DISCUSSION}

This is the first study from this country presenting the risk factors for COVID-19 admitted in Indus hospital Karachi, a tertiary care hospital. There is a vast difference in the incidence, prevalence and case fatality rate observed in the two economically divided worlds (the developing and the developed world). The possible explanation could be the differences in factors like social behavior, concept of hygiene emerged in the western countries and expropriation of health from physician to state over the last 200 years after industrialization and development [12]-[14].

In our population females were less effected, admitted and faced death as compared to males, as observed in other studies too, although this effect was lost in adjusted analysis [15]. There are many hypotheses for this gender difference for the predilection of COVID-19 in males and protection for the females. Firstly, in comparison with innate and acquired immunity, females have higher counts of CD4+ T cells, more vigorous $\mathrm{CD} 8+\mathrm{T}$ cell cytotoxic projection, and increased production of immunoglobulin from $\mathrm{B}$ cell compared to males. Secondly, females produce more interferon type I. Thirdly, the $\mathrm{X}$ chromosomes contain many immune related genes and lastly, there is an effect of estradiol enhancement on immune system [16]. But the effect of all these factors in our population is hard to predict as overall health status of female in our society is not according to the definition of health by WHO [17]. On the other hand, social behavior like hand washing was also thought to be a cause of low prevalence of COVID-19 in females, as it is an observation that hand washing is mostly practiced by female in a natural setting [18]. The social practice of hand washing before and after meal and after using washroom along with offering prayers which need not only washing of hand, but cleaning of nose and throat might have protective effect in Muslim community like Pakistan [19], [20].

Among the co-morbid condition, we found hypertension played an important role in increasing mortality. In a metaanalysis of 71 studies comprising 216,843 patients' hypertension was significantly associated with death. We did not find any association of DM, IHD, and CCF with mortality [15]. Patients who were complicated with acute kidney injury in our population showed devastating outcome and acute kidney injury in COVID-19 patients recognized as predictor [21], [22].

Effect of treatment was also not very encouraging in our patients. Methylprednisolone, Remdesivir, Tocilizumab and Hydroxychloroquine were used in different patients according to the WHO and local guidelines. The overall impact of treatment was not supportive in improving the survival, also concluded recently in a large, randomized trial [23].

Among laboratory parameters we found a significant effect of high TLC and low lymphocyte count, low albumin high LDH on mortality, but in multivariate analysis AKI and ACS high TLC, low albumin, hypernatremia, and hyperkalemia were significantly associated with bad outcome. This effect was also observed in other studies [24].

Our study has few limitations because of its observational nature and retrospective data collection, although the sample size is adequate, and no other data is published with this number from this country. The impact of COVID-19 is severe all around the world but surprisingly it affected the developed nations more gravely than the developing countries. The possible explanation could be the different epidemiological factors observed during the epidemic, as we mentioned, rich economy, high GDP, high education, concept of hygiene does not prove to provide protection from epidemic [9], [12]. The epidemiology and demography of COVID-19 is different in this population. Therefore, despite the presence of the traditional risk factors which were thought will deteriorate the outcome of the disease in this population, the mortality was not as high as we are still observing in the western population.

\section{CONCLUSION}

We concluded that there is a dire need of reassessing the traditional risk factors associated with viral epidemic and understanding the changing paradigm of epidemiology emerging out from this epidemic in both developed and developing counties. There is an obligation to have more data from developing world to elucidate the risk factors, so that people and countries can protect themselves with this new dynamic of disease spread observed in corona pandemic.

\section{ACKNOWLEDGMENT}

We acknowledge the contribution of Ms. Yumna Maheen and Dr Jahanzeb Khan in preparation of manuscript.

\section{AUTHORSHIP}

All named authors meet the International Committee of Medical Journal Editors (ICMJE) criteria for authorship for this article, take responsibility for the integrity of the work as a whole, and have given their approval for this version to be published.

\section{DISCLOSURES}

The authors declare that they have no conflict of interest. 


\section{COMPLIANCE WITH ETHICS GUIDELINES}

We have received a waiver of consent from the institutional review board (IRD_IRB_2020_04_017).

\section{DATA AVAILABILITY}

The datasets generated and analyzed during the current study are available from the corresponding author on reasonable request.

\section{REFERENCES}

[1] WHO. Coronavirus disease 2019: Situation report.93.2020.

[2] Zhou F, Yu T, Du R, Fan G, Liu Y, Liu Z, Xiang J, Wang Y, Song B, $\mathrm{Gu}$ X, Guan L. Clinical course and risk factors for mortality of adult inpatients with COVID-19 in Wuhan, China: a retrospective cohort study. The lancet. 2020 Mar 28;395(10229):1054-62.

[3] Ho FK, Celis-Morales CA, Gray SR, Katikireddi SV, Niedzwiedz CL, Hastie C, Lyall DM, Ferguson LD, Berry C, Mackay DF, Gill JM. Modifiable and non-modifiable risk factors for COVID-19: results from UK Biobank. MedRxiv. 2020 Jan 1.

[4] Ahrenfeldt LJ, Nielsen CR, Möller S, Christensen K, Lindahl-Jacobsen R. Burden and prevalence of risk factors for severe COVID-19 disease in the ageing European population-A SHARE-based analysis.

[5] Wang J, Guo S, Zhang Y, Gao K, Zuo J, Tan N, Du K, Ma Y, Hou Y, $\mathrm{Li} \mathrm{Q}, \mathrm{Xu} \mathrm{H}$. Clinical features and risk factors for severe inpatients with COVID-19: A retrospective study in China. PloS one. 2020 Dec 17;15(12):e0244125.

[6] Anwar S, Nasrullah M, Hosen MJ. COVID-19 and Bangladesh: Challenges and how to address them. Frontiers in public health. 2020;8.

[7] Laxminarayan R, Wahl B, Dudala SR, Gopal K, Neelima S, Reddy KJ, Radhakrishnan J, Lewnard JA. Epidemiology and transmission dynamics of COVID-19 in two Indian states. Science. 2020 Nov 6;370(6517):691-7.

[8] WHO corona disease dashboard visited on 7 Jan 2021.

[9] Sorci G, Faivre B, Morand S. Explaining among-country variation in COVID-19 case fatality rate. Scientific reports. 2020 Nov 3;10(1):1-1.

[10] Atif M, Malik I. Why is Pakistan vulnerable to COVID-19 associated morbidity and mortality? A scoping review. The International journal of health planning and management. 2020 Sep;35(5):1041-54.
[11] Shah S. Why Youthful, Conservative Pakistan Is a Coronavirus Bright Spot. The Wall Street Journal. 2020;1.

[12] Morand S, Walther BA. Individualistic values are related to an increase in the outbreaks of infectious diseases and zoonotic diseases. Scientific reports. 2018 Mar 1;8(1):1-9.

[13] Bashford A. Imperial hygiene: a critical history of colonialism, nationalism and public health. Springer; 2003 Nov 11.

[14] Illich I. Medical nemesis. Australian Broadcasting Commission, Science Programmes Unit; 1975.

[15] Degarege A, Naveed Z, Kabayundo J, Brett-Major D. Risk factors for severe illness and death in COVID-19: a systematic review and metaanalysis. medRxiv. 2020 Jan 1.

[16] Peckham H, de Gruijter NM, Raine C, Radziszewska A, Ciurtin C, Wedderburn LR, Rosser EC, Webb K, Deakin CT. Male sex identified by global COVID-19 meta-analysis as a risk factor for death and ITU admission. Nature communications. 2020 Dec 9;11(1):1-0.

[17] Women's health - WHO | World Health Organization www.who.int > Health topics > Women's health.

[18] Judah G, Aunger R, Schmidt WP, Michie S, Granger S, Curtis V. Experimental pretesting of hand-washing interventions in a natural setting. American journal of public health. 2009 Oct;99(S2):S405-11.

[19] Allegranzi B, Memish ZA, Donaldson L, Pittet D, Safety WH, on Religious CT. Religion and culture: potential undercurrents influencing hand hygiene promotion in health care. American journal of infection control. 2009 Feb 1;37(1):28-34.

[20] Katme AM. Muslim teaching gives rules for when hands must be washed. BMJ. 1999 Aug 21;319(7208):518.

[21] Fisher M, Neugarten J, Bellin E, Yunes M, Stahl L, Johns TS, Abramowitz MK, Levy R, Kumar N, Mokrzycki MH, Coco M. AKI in Hospitalized Patients with and without COVID-19: A Comparison Study. Journal of the American Society of Nephrology. 2020 Sep 1;31(9):2145-57.

[22] Chan L, Chaudhary K, Saha A, Chauhan K, Vaid A, Zhao S, Paranjpe I, Somani S, Richter F, Miotto R, Lala A. AKI in hospitalized patients with COVID-19. Journal of the American Society of Nephrology. 2021 Jan 1;32(1):151-60.

[23] WHO Solidarity Trial Consortium. Repurposed antiviral drugs for Covid-19 - interim WHO Solidarity trial results. N Engl J Med 2021;384:497-511.

[24] Bai T, Tu S, Wei Y, Xiao L, Jin Y, Zhang L, Song J, Liu W, Zhu Q, Yang L, Chen $\mathrm{H}$. Clinical and laboratory factors predicting the prognosis of patients with COVID-19: an analysis of 127 patients in Wuhan, China. China (2/26/2020). 2020 Feb 26. 